\title{
Destruction of the C2 Body due to Cervical Actinomycosis Connection between Spinal Epidural Abscess and Retropharyngeal Abscess
}

\section{Dong Min Kim", Seok Won Kim²}

Departments of ${ }^{1}$ Internal Medicine and ${ }^{2}$ Neurosurgery, Chosun University College of Medicine, Gwangju, Korea

Corresponding Author:

Seok Won Kim

Department of Neurosurgery, Chosun University College of Medicine, 365 Pilmun-daero, Dong-gu, Gwangju 61453, Korea

Tel: +82-62-220-3126

Fax: +82-62-227-4575

E-mail: chosunns@chosun.ac.kr

Received: December 12, 2016

Revised: March 15, 2017

Accepted: March 17, 2017
Copyright (C 2017 by The Korean Spinal Neurosurgery Society

This is an open access article distributed under the terms of the Creative Commons Attribution Non-Commercial License (http://creativecommons.org/licenses/by-n $\mathrm{c} / 4.0 /$ ) which permits unrestricted non-commercial use, distribution, and reproduction in any medium, provided the original work is properly cited.

Human actinomycosis with involvement of the spine is a rare condition, with only a limited number of case reports published. To the best of our knowledge, no cases have been reported of epidural abscess causing destruction of the $\mathrm{C} 2$ body, bringing about a direct connection between spinal epidural and retropharyngeal abscesses. Here, we present such a case that occurred after acupuncture, and we review the relevant literature.

Key Words: Cervical, Actinomycosis, Abscess

\section{INTRODUCTION}

Actinomycosis is a chronic suppurative infection caused by Actinomyces spp. which are facul tative, anaerobic, branching, gram-positive, acid-fast negative bacilli belonging to the normal flora of the oropharyngeal cavity ${ }^{1)}$.

The diagnosis of spinal actinomycosis is quite challenging due to its rarity, insidious evolution, mimicking, and the specific procedures required to accurately identify the pathogen. Moreover, upper cervical actinomycosis involving the atlas and axis is distinctly unusual, and may lead to the destruction of the vertebral body. Although rare, it is a neurosurgical emergency that results in severe morbidity and mortality in case of delayed diagnosis or inappropriate treatment for cervical epidural abscess or retropharyngeal abscess.

Here, we report the destruction of the $\mathrm{C} 2$ body due to a cervical actinomycosis abscess, causing a direct connection between the retropharyngeal and spinal epidural abscesses. Knowledge of this case and its pathophysiology are important to ensure that the necessary precautions are taken in the future, because there are limited numbers of similar cases.

\section{CASE REPORT}

A 44-year-old man was transferred to our Emergency Department (ED) from a traditional oriental hospital for painful swelling in the upper cervical region and for motor weakness. He had suffered from diabetes for 5 years and had undergone acupuncture procedures several times for nuchal pain in the traditional oriental hospital. A physical examination revealed painful swelling in the upper cervical region. His body temperature was $38.3^{\circ} \mathrm{C}$ when he was transferred to the ED. A neurologic examination revealed grade 3 paraparesis in the upper extremities and grade 2 in the lower extremities. Hematologic analysis demonstrated that his white blood cell count was $12,800 / \mathrm{mL}$, with an erythrocyte sedimentation rate of $46 \mathrm{~mm} / \mathrm{hr}$ and a C-reactive protein level of $19.8 \mathrm{mg} / \mathrm{dL}$. Bilateral plantar reflex was observed on neurologic examination. Computed tomography (CT) scan of the cervical spine revealed complete destruction of the C2 body and multiple areas of bone resorption with a "punched out" appearance (Fig. 1).

Magnetic resonance imaging (MRI) showed extensive contrast-enhanced retropharyngeal and spinal epidural abscesses in the upper cervical region with the destruction of the $\mathrm{C} 2$ body and severe cord compression (Fig. 2).

Following a diagnosis of osteomyelitis with cord compression, an emergency surgery for abscess drainage was performed under general anesthesia. The patient underwent combined surgery for removal of pus. The anterior approach was carried out by an otorhinolaryngology team and decompressive laminectomy for cord decompression was performed by a neurosurgical team. A yellowish purulent material was identified and a large amount of pus was drained. Actinomyces spp. was isolated from the pus and the same pathogen was isolated from the patient's blood culture stains for acid-fast bacilli; mycobacterial cultures were negative. The patient was transferred to the Infectious Internal Medicine Department for further antibiotic treatment. 


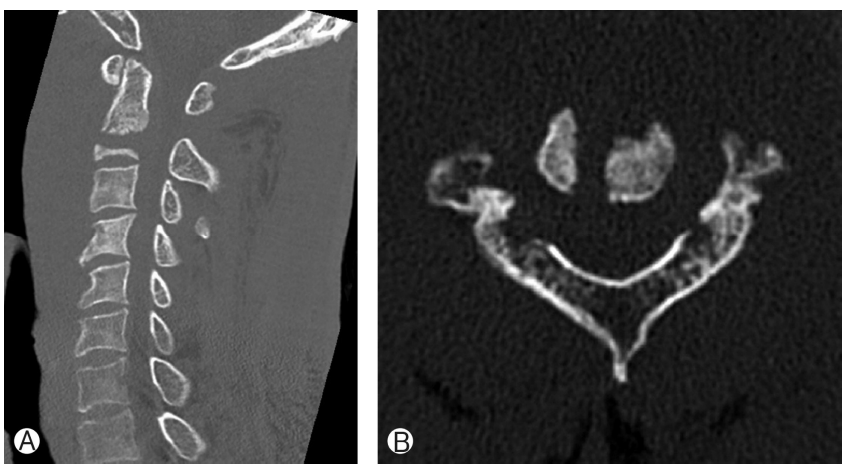

Fig. 1. Sagittal (A) and axial (B) computed tomography scans reveal multiple punched out-like bone resorption and complete destruction of the $\mathrm{C} 2$ body.
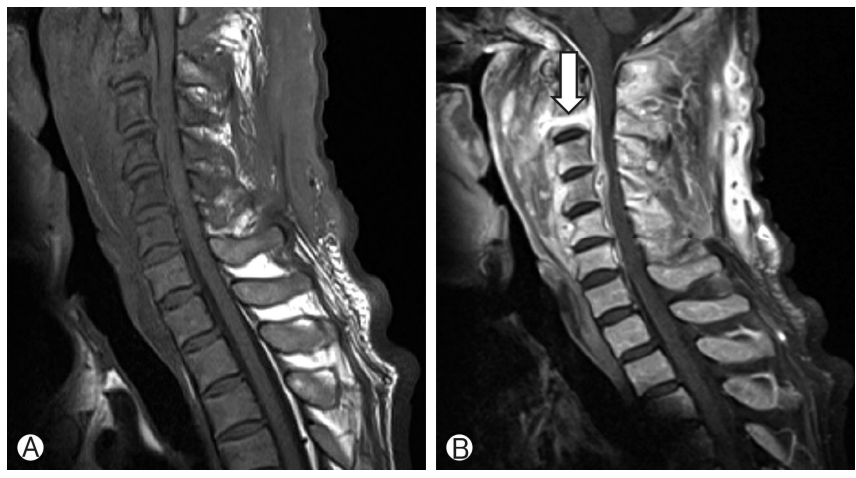

Fig. 2. T2-weighted (A) and gadolinium-enhanced T1-weighted (B) magnetic resonance images demonstrate multifocal abscess and a direct connection between the spinal epidural and retropharyngeal abscesses (arrow).

Initially the patient was started empirically on intravenous antibiotics, consisting of cefazolin and vancomycin. The antibiotic regimen was changed to erythromycin. During the follow-up examination at 6 months after surgery, the patient had completely recovered from the painful swelling in the upper cervical region. However, the neck discomfort, positive plantar reflex, and paraparesis persisted.

\section{DISCUSSION}

Members of the Actinomyces genus are fastidious, facultative, anaerobic, gram-positive, and acid-fast negative branching bacilli. Actinomyces spp. are considered opportunistic pathogens in humans, belonging to the normal flora of the oropharyngeal cavity. The bacterium can result in infection either in immunocompetent or immunocompromised patients, notably when a break in the mucosa of the gastrointestinal tract occurs between the oral cavity and the rectum. Thus, there are numerous risk factors for actinomycosis, including dental care, sepsis, abdominal surgery, diverticulitis, or the use of intrauterine and intravaginal devices $^{2,8)}$.

Spinal involvement is an exceptional feature, and represents less than $5 \%$ of the concerned sites. It is usually secondary to infection of contiguous tissues rather than to hematogenous spread. Differential diagnoses include all chronic and suppurative infectious processes. The main differential diagnoses are nocardiosis, tuberculosis, spondyloarthritis, and primary or secondary malignancies $^{10)}$.

The diagnosis of actinomycosis requires a high degree of clinical suspicion, since Actinomyces spp. are insidious organisms and infections with these organisms may show only nonspecific clinical manifestations ${ }^{9}$.

Immunosuppressed patients with diabetes mellitus are more prone to spinal abscess and osteomyelitis. Immunosuppressed patients with diabetes mellitus are more prone to spinal abscess and osteomyelitis. Remarkably, the patient in this case had diabetes mellitus and had undergone acupuncture procedures in a traditional oriental hospital. Infection is one of the most frequent complications that occurs after acupuncture procedure, and is largely divided into local and systemic forms.

Although various gram-positive or gram-negative tuberculous and anaerobic bacteria have been reported as infectious agents, Staphylococcus spp. is the most common cause of spinal abscess ${ }^{4)}$.

Spondylitis or epidural abscess due to Actinomyces spp. is an exceptional feature. However, this diagnosis must be considered in case of an insidious spondylitis in a patient with consistent exposure conditions. In addition, accurate identification of species relies on 16s rRNA sequencing and analysis ${ }^{5)}$. Diagnostic tests to evaluate the bone for osteomyelitis include plain radiography, CT, and contrast MRI. Among them, MRI is the most reliable diagnostic tool for identifying tissue inflammation and spinal cord compression.

The treatment of actinomycosis includes antimicrobial therapy with or without surgery. Penicillin is the cornerstone of the treatment of actinomycosis. However, Actinomyces spp. are susceptible to various antimicrobials, including tetracyclines, erythromycin, clindamycin, and chloramphenicol ${ }^{6}$.

The optimal duration of antimicrobial therapy should be tailored to the severity of illness. However, a longer duration of treatment with antimicrobial agents is usually necessary, since the premature termination of antimicrobial therapy may cause a relapse of actinomycosis. A long duration of treatment is generally suitable to prevent relapses and a combined medico-surgical approach is required for complicated forms of the disease ${ }^{3,7,11)}$.

The present case is unusual due to the extensive abscess caused by rare actinomycosis that destroyed the $\mathrm{C} 2$ body, with direct connection between retropharyngeal and upper cervical epidural abscesses, which needed combined anterior and posterior surgical approaches.

\section{CONCLUSION}

Destruction of the C2 body due to cervical vertebral actinomycosis is an exceptional feature. Although rare, neurologic deficits seem to be irreversible if the patient is not treated appropriately and rapidly. It is crucial for physicians to be aware of this 
serious condition.

\section{CONFLICT OF INTEREST}

No potential conflict of interest relevant to this article was reported.

\section{REFERENCES}

1. Duvignaud A, Ribeiro E, Moynet D, Longy-Boursier M, Malvy D: Cervical spondylitis and spinal abscess due to Actinomyces meyeri. Braz J Infect Dis 18:106-109, 2014

2. Honda H, Bankowski MJ, Kajioka EH, Chokrungvaranon N, Kim W, Gallacher ST: Thoracic vertebral actinomycosis: actinomyces israelii and Fusobacterium nucleatum. J Clin Microbiol 46:20092014, 2008

3. Hong WJ, Lee SG, Park CW, Kim WK, Yoo CJ: Awareness for serious spinal complications predicted after acupuncture procedures for pain control. J Korean Neurosurg Soc 36:130-134, 2004

4. Ju MW, Choi SW, Kwon HJ, Kim SH, Koh HS, Youm JY, et al: Treatment of spinal epidural abscess and predisposing factors of motor weakness: experience with 48 patients. Korean J Spine 12:124-129, 2015

5. Kricun R, Shoemaker EI, Chovanes GI, Stephens HW: Epidural abscess of the cervical spine: MR findings in five cases. AJR Am J Roentgenol 158:1145-1149, 1992

6. Martin MV: Antibiotic treatment of cervicofacial actinomycosis for patients allergic to penicillin: a clinical and in vitro study. $\mathrm{Br}$ J Oral Maxillofac Surg 23:428-434, 1985

7. Rigamonti D, Liem L, Wolf AL, Fiandaca MS, Numaguchi Y, Hsu FP, et al: Epidural abscess in the cervical spine. Mt Sinai J Med 61:357-362, 1994

8. Smego RA Jr, Foglia G: Actinomycosis. Clin Infect Dis 26:12551261, 1998

9. Varshney MK, Trikha V, Khan SA: Actinomycosis or tuberculosis? A diagnostic dilemma. Scand J Infect Dis 38:378-381, 2006

10. Voisin L, Vittecoq O, Mejjad O, Krzanowska C, Defives T, Cambon-Michot C, et al: Spinal abscess and spondylitis due to actinomycosis. Spine (Phila Pa 1976) 23:487-490, 1998

11. Yung BC, Cheng JC, Chan TT, Loke TK, Lo J, Lau PY: Aggressive thoracic actinomycosis complicated by vertebral osteomyelitis and epidural abscess leading to spinal cord compression. Spine (Phila Pa 1976) 25:745-748, 2000 